\title{
Graph-analytical method of load mode analysis of ferromagnetic current stabilizer
}

\author{
A $N$ Rasulov $^{1}, G R$ Rafikova $^{1}, N L$ Novikov $^{2}, M R$ Ruzinazarov $^{1}$, Esemuratova $^{3}$ \\ ${ }^{1}$ Tashkent state technical university named after Islam Karimov, Tashkent, Uzbekistan \\ ${ }^{2}$ National Research University Moscow Power Engineering Institute \\ ${ }^{3}$ Karakalpak State University
}

\begin{abstract}
In this paper we consider the application of graph-analytical method for the analysis of the load regime of ferromagnetic current stabilizer. It is proved that under active load the current of the ferromagnetic stabilizer and magnetic flux are related by the ellipse equation where the axes coincide with the axes of coordinate system. The advantage of the proposed method is that it is possible to use an experimentally obtained characteristic.
\end{abstract}

\section{Introduction}

When analyzing the circuit of ferromagnetic current stabilizer (Fig.1) for complex load it is convenient to use graph-analytical method by solving algebraic equations of the system. Let's assume that we know the characteristic $\mathrm{X}_{\mathrm{M}}=\mathrm{f}\left(\mathrm{Z}_{\mathrm{M}}\right)$ of current stabilizer circuit which can be determined based on the magnetization curve of the ferromagnetic element and the characteristic of the compensating capacitance. [1-8].

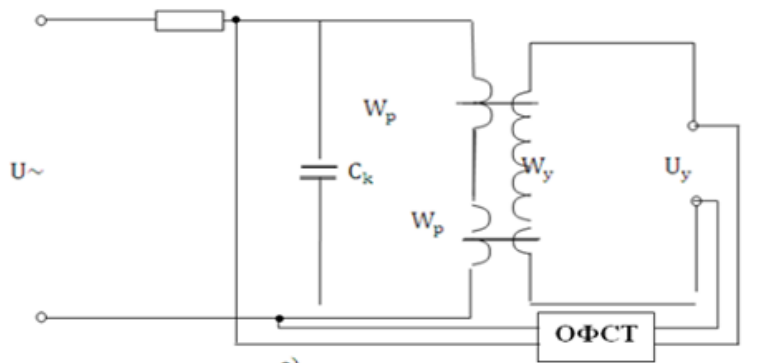

Fig. 1. Schematic diagram of a ferromagnetic current stabilizer

For an active inductive load

$$
u=L_{H} \frac{\omega_{c t}}{d t}+r_{H} i_{c t}+2 W \frac{\alpha \phi}{d t}
$$

$$
\begin{aligned}
& \text { Given that } \quad Z_{c}=\frac{1}{m} \frac{d^{2} x^{2}}{d \tau^{2}} \\
& y=Y_{m} \cos (\tau+\varphi) \\
& x=X_{m} \sin \tau \quad z_{\phi p}=Z_{m \phi o} \sin \tau
\end{aligned}
$$

after introducing the normalized values we have

$$
\text { If } \begin{gathered}
Y_{m}^{2}=\left(\delta^{2}+\gamma_{H}\right) Z_{m c t}^{2}+X_{m}^{2}+2 \gamma_{H} Z_{m c t} X_{m} \\
\gamma_{H}=0 \quad Y_{m}^{2}=\delta^{2} Z_{m c t}^{2}+X_{m}^{2}
\end{gathered}
$$

or

$$
\frac{Z_{m c t}^{2}}{\frac{Z_{m c t}^{2}}{\delta^{2}}}+\frac{X_{m}^{2}}{Y_{m}^{2}}
$$

From this it can be seen that under active load, the current of the ferromagnetic stabiliser and the magnetic flux are related by the equation of an ellipse whose axes coincide with the axes of the coordinate system. On the other hand, these quantities are related by the circuit characteristic of the ferromagnetic current stabiliser. Thus, by superimposing the ellipse on the circuit characteristics of a ferroresonant current stabiliser, the operating mode can be determined. Abscissa of intersection point of ellipse with circuit characteristic shows operating current and ordinate of flux in the core of the ferromagnetic element (fig.2) [9-14].

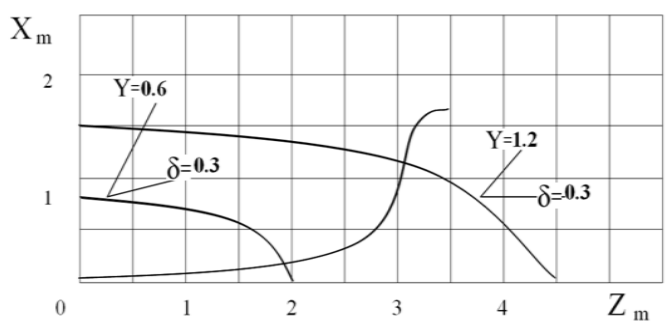

Fig. 2. DependenceXm=f(Zm).

If $\gamma \neq 0, \mathrm{Zm}, \mathrm{Xm}$ are also related by the equation of the ellipse where the centre coincides with the origin. The axis of 
the ellipse has some angle with respect to the axis of coordinates. Using previously discussed methodology, let's write equation (3) in following form.

$$
\frac{\frac{Z_{m}^{2}}{Y_{m}^{2}}}{A}+\frac{X_{m}^{2}}{Y_{m}^{2}}
$$

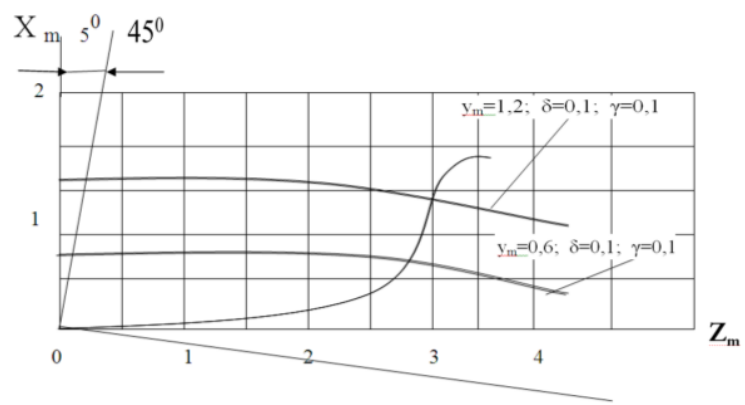

Fig. 3. Dependencies $X m=f(Z$.m)for the case $\gamma \neq 0$

$$
\begin{aligned}
& A=\left(\delta^{2}+\gamma_{H}^{2}\right) \cos ^{2} \alpha+\sin ^{2} \alpha+2 \gamma_{H} \sin \alpha \cos \alpha \\
& C=\left(\delta^{2}+\gamma_{H}^{2}\right) \sin ^{2} \alpha+\cos ^{2} \alpha+2 \gamma_{H} \sin \alpha \cos \alpha
\end{aligned}
$$

$$
\operatorname{tg} \alpha=\frac{2 \gamma}{\delta^{2}+\gamma_{H}-1}
$$

$\alpha$ is rotation angle of ellipse axes,

$\mathrm{Z}_{\mathrm{m}}, \mathrm{X}_{\mathrm{m}}$ - new coordinates.

Fig.3 shows ellipses for different values of input voltage at inductive nature of load and relationship $\mathrm{Zm}=\mathrm{f}(\mathrm{Xm})$ of ferromagnetic current stabilizer circuit. Here $\alpha$ has a negative sign which means that the coordinate system of axes of an ellipse is rotated clockwise. [15-22]

When the nature of the load is active-capacitive, the circuit equation of state is as follows:

$$
\frac{d u}{d t}=\frac{i}{c}+R \frac{d i}{d t}+2 W \frac{d^{2} \phi}{d t^{2}}
$$

From where

$$
Y_{m}^{2}=\left(\delta^{2}+\gamma^{2}\right) X_{m}^{2}+X_{m}^{2}+2 \gamma Z_{m} X_{m}
$$

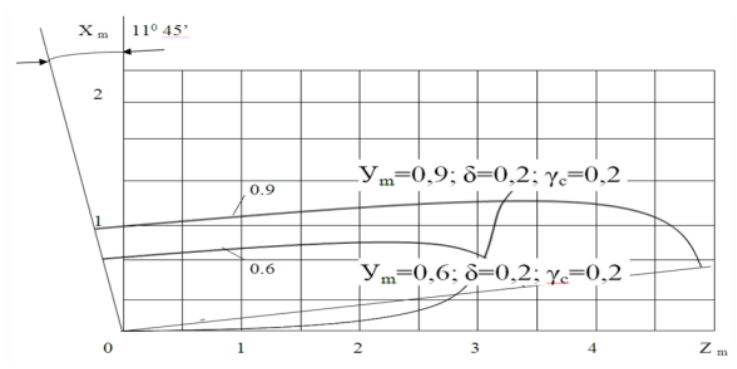

Fig. 4. Dependencies $X m=f(Z m)$ for the case $\gamma \neq 0$

Further investigation of dependence (11) has shown that expressions similar to (6), (7), (8), (9), differing only by signs before coefficients $\gamma \mathrm{n}$ and $\gamma$. Angle of rotation of ellipse axes has positive sign (fig. 4). Thus, the advantage of the analysis by graph-analytical method is that it is possible to use experimentally obtained characteristic of the device.

\section{References}

1. Bessonov L.A. Theoretical fundamentals of electrical engineering. Electrical circuits. Textbook. 10th ed. M.Gardarmki 2002.638s.

2. Volkov I.V., Gubarevich V.N., Isakov V.N., Kaban V.P. Principles of Construction and Optimisation of InductanceCapacitor Circuits. Kiev Naukova Dumka, 1981-174p.

3. Rasulov A.N., Rafikova G.R., Ruzinazarov M.R. Current stabilization on the basis of magnetic amplifier with electromagnetic control circuit. The problems of energy and resource saving 3-4. 2020Г -312-317

4. F.A.Hoshimov, I.I.Bakhadirov, M.S.Kurbanbayeva, N.A.Aytbayev. Development of specific standards of energy consumption by types of produced products of the spinning product // RSES 2020. E3S Web of Conferences. 216 (2020) 01169. https://doi.org/10.1051/e3sconf/202021601169

5. F.A.Hoshimov, I.I.Bakhadirov, A.A.Alimov, M.T.Erejepov. Forecasting the electric consumption of objects using artificial neural networks // E3S Web of $\begin{array}{llll}\text { Conferences. } & 216 & \text { (2020) } & 01170 .\end{array}$ https://doi.org/10.1051/e3sconf/202021601170

6. R.Karimov, M.Bobojanov. Analysis of voltage stabilizers and non-contact relays in power supply systems // RSES 2020. E3S Web of Conferences. 216 (2020) 01162. https://doi.org/10.1051/e3sconf/202021601162

7. R.Karimov. Study of the state of the issue of increasing the quality of electric energy in the power supply systems // RSES 2020. E3S Web of Conferences. 216 (2020) 01163. https://doi.org/10.1051/e3sconf/202021601163

8. I.U.Rakhmonov, A.N.Tovbaev, L.A.Nematov and T.Sh.Alibekova. Development of forecasted values of specific norms for the issues of produced products in industrial enterprises // ICMSIT-2020. Journal of Physics: Conference Series. 1515 (2020) 022050. doi:10.1088/17426596/1515/2/022050

9. I.U.Rakhmonov, L.Nematov, N.N.Niyozov, K.M.Reymov, T.Yuldoshev. Power consumption management from the positions of the general system theory // ICMSIT-2020. Journal of Physics: Conference Series. 1515 (2020) 022054. doi:10.1088/1742-6596/1515/2/022054

10. I.U.Rakhmonov, F.A.Hoshimov. Development of an algorithm for evaluating the dominant factors that have the greatest impact on the energy intensity of products // ENERGY-21. E3S Web of Conferences. 209 (2020) 07018. https://doi.org/10.1051/e3sconf/202020907018

11. Usmanov E.G. Stability in a parallel resonant circuit with active load // RSES 2020. E3S Web of Conferences. 216 (2020) 01160. https://doi.org/10.1051/e3sconf/202021601160 12. Usmanov E.G., Khusanov B.M. Phase relations in resonant circuits with a wide falling section on the amplitude 
characteristic // RSES 2020. E3S Web of Conferences. 216 (2020) 01161. https://doi.org/10.1051/e3sconf/202021601161 13. I.U.Rakhmonov, K.M.Reymov and S.H.Dustova. Improvements in industrial energy rationing methods // MIP: Engineering-2020. E3S Web of Conferences. 862 (2020) 062070. doi:10.1088/1757-899X/862/6/062070

14. I.U.Rakhmonov, K.M.Reymov. Statistical models of renewable energy intermittency // RSES 2020. E3S Web of Conferences. $216 \quad 01167$. https://doi.org/10.1051/e3sconf/202021601167

15. I.U.Rakhmonov, N.N.Kurbonov. Analysis of automated software for monitoring energy consumption and efficiency of industrial enterprises // E3S Web of Conferences. 216 (2020) 01178. https://doi.org/10.1051/e3sconf/202021601178 16. F.A.Hoshimov, I.U.Rakhmonov, N.N.Niyozov. Technology to reduce energy costs in the electric steel melting shop // ENERGY-21. E3S Web of Conferences. 209 (2020) 07017. https://doi.org/10.1051/e3sconf/202020907017 17. A.Taslimov, F.Rakhimov, L.Nematov, N.Markaev, A.Bijanov, R.Yunusov. Economic load intervals for selecting $10 \mathrm{kV}$ cable cross-sections for agricultural consumers // CONMECHYDRO - 2020. IOP Conf. Series: Materials Science and Engineering. $883 \quad$ (2020) 012102. doi:10.1088/1757-899X/883/1/012102

18. Hadha Afrisal, Budi Setiyono, Muhammad Fahmi Yusuf, Rose Mutiara Suin, Olimjon Toirov 2020 7th International Conference on Information Technology, Computer, and Electrical Engineering (ICITACEE), pp. 4146 (2020), https://doi.org/10.1109/ICITACEE50144.2020.9239228

19. Olimjon Toirov, Sardor Urokov, Utkir Mirkhonov, Hadha Afrisal, Dilnoza Jumaeva Experimental study of the control of operating modes of a plate feeder based on a frequency-controlled electric drive, E3S Web of Conferences, SUSE-2021 (2021)

20. E.Usmanov, A.Rasulov, M.K.Bobojanov, R.Ch.Karimov. Non-contact voltage relay for switching windings of a boost transformer (E3S Web of Conferences, 139, 01079, 2019), https://doi.org/10.1051/e3sconf/201913901079

21. Toshov J.B. The questions of the dynamics of drilling bit on the surface of well bottom// Arch. Min. Sci. - Poland. Vol. 61 (2016), № 2, P. 279-287. DOI 10.1515/amsc-20160020

22. Karimov R.Ch., Bobojanov M.K., Rasulov A.N., Usmanov E.G. Controlled switching circuits based on nonlinear resistive elements (E3S Web of Conferences, 139, 01039, 2019), https://doi.org/10.1051/e3sconf/201913901039 